\title{
Healing Cream Tournefortia hirsutissima L
}

\section{Gabriela Rivera Hernández, Daisy Yara Hernández García and Mirna Lorena Sanchez*}

Department of Biotechnology, Chair of Food Development and Bioproducts, Technological Institute of Higher Education of Monterrey, Campus Puebla, Mexico

*Corresponding author: Mirna Lorena Sánchez, Department of Biotechnology, Chair of Food Development and Bioproducts, Technological Institute of Higher Education of Monterrey, Puebla Campus, Mexico, Tel: 222623 9315; E-mail: mirna.sanchez@itesm.mx

Received date: May 05, 2017; Accepted date: July 06, 2017; Published date: July 11, 2017

Copyright: @ 2017 Gabriela RH, et al. This is an open-access article distributed under the terms of the Creative Commons Attribution License, which permits unrestricted use, distribution, and reproduction in any medium, provided the original author and source are credited.

\section{Abstract}

Objective: Investigate the active compounds of Tournefortia hirsutissima L. to determine the compounds responsible for the cicatrizing effect. Furthermore, create a topic formulation with the extract of the plant to accelerate the healing process.

Methods: The compounds of the plant were characterized before with a Gas Chromatography- Mass Spectrometry (GC-MS). To extract the compounds, it was used a steam distillation, solvent extraction and Microwave Assisted Extraction (MAE) and it was compared the efficiency of each method. A

Results: After the investigation of each compound, it was found that palmitic acid induces the regeneration of keratocytes. Furthermore gamma-sitosterol accelerates keratinocyte migration by eliminating ROS. In the extraction methods of Tournefortia hirsutissima L. and carrot, the Microwave Assisted Extraction had the best efficiency. An inhibitory halo, around the cream and the extract of the plant, was shown in the antibiogram using a massive spread of Staphylococcus aureus.

Conclusion: After the investigation of each compounds of Tournefortia hirsutissima L., it can be concluded that plant has compounds that accelerate healing by inducing the production of keratocytes in the skin and reduce levels of oxidative stress. Furthermore, the plant inhibits growth of Staphylococcus aureus, so the plant has an antibiotic effect.

Keywords: Tournefortia hirsutissima L; Tlachichinoa; Palmitic acid; Gamma-sitosterol; Healing acceleration; Production of keratocytes; Reduce oxidative stress

\section{Introduction}

A wound is an injury that causes a break in the skin, damage the surrounding tissue. Chronic wounds, such as deep ulcers (open sores), large burns and infected cuts, can not heal completely in 6 weeks. The increase of metabolic diseases, such as type 2 diabetes, have led to a similar increase in comorbidities related to chronic wounds, such as diabetic foot [1]. In Mexico there is also an epidemiological situation of chronic wounds, the Ministry of Health has promoted the implementation of Wound Clinics, which seek the standardization of comprehensive care of patients. Furthermore, in Mexico, the pressure ulcers occur in $12.92 \%$ of patients and it is estimated that diabetic foot syndrome affects approximately $15 \%$ of patients [2].

Medicinal plant treatments have been proposed with successful results for diabetic foot wounds and ulcers. These treatments include the use of some native medicinal plants from central and southern Mexico. In this group of plants are the specimens Tournefortia hirsutissima L., commonly known as "Tlachichinoa" or "Tlachichinole". This plant belongs to a genus of flowering plants and pharmacological properties inherent to the Boraginaceae family [3].

\section{Materials and Methods}

In order to generate new knowledge and potentially innovative healing mechanisms, scientists from the Benemérita Autonomous University of Puebla carried out a research work to know its components. The characterization of this plant was performed by the following methods: Gas chromatography- coupled to mass spectrometry (GS-MS), X-ray diffraction (XRD) and scanning electron microscopy (SEM) [3]. To understand which of these compounds are involved in the healing acceleration process it was investigated each of them to characterize their functions.

After, different extraction methods were used to compare the efficiency and choose the best option to production of the extract.

\section{Plant material}

The leaves of Tournefortia hirsutissima L. were collected from Tecomatlán, Puebla, Mexico, in April 2017 and dried for 7 days. Hydrated and dehydrated carrots (for 7 days) were collected in San Martín Texmelucan, Puebla, Mexico in April. 2017.

\section{Preparation of the extract}

Extraction of compounds of Tournefortia Hirsutissima by distillation: The extraction of $Y$-sistosterol and palmitic acid from the Tournefortia hirsutissima L. plant was carried out by steam distillation. It was used $48.94 \mathrm{~g}$ of Tournefortia hirsutissima $\mathrm{L}$. and as reagents were used ethyl acetate and anhydrous sodium sulfate. For the extraction of these compounds, the plant was placed in small pieces in the 
distillation equipment, taking care that the temperature was not higher than $100^{\circ} \mathrm{C}$. When $100 \mathrm{ml}$ of distillate was obtained, it was poured into a separatory funnel. In order to facilitate separation, acetate was added and homogeneously mixed. The aqueous phase was discarded and anhydrous sodium sulfate added to the organic part of the distillate.

Extraction of retinol and $\beta$-carotene compounds by solvent extraction: Retinol and $\beta$-carotenes were extracted from $100 \mathrm{~g}$ of carrots with hexane as a solvent. The carrot in a puree was boiled for 15 minutes and hexane was added. It was allowed to stand for 10 minutes and then the hexane was decanted in a separator funnel and $50 \mathrm{ml}$ of ethanol was added. The two phases were collected separately and tests were performed to detect the presence of beta-carotene and retinol.

Retinol and B-carotene microwave assisted extraction: I was used $250 \mathrm{~g}$ of dried carrots into small pieces. A solution of $150 \mathrm{ml}$ of ethanol was prepared and the carrot was placed in the flask by adding ethanol. The contents of the flask were stirred until the solution was homogenized and the mixture was heated in the microwave for 4 minutes, stopping every time it started to boil. We also did a filtration with a 0.45 microfilter.

Microwave assisted extraction of Tournefortia hirsutissima L.: The extraction of Y-sistosterol and palmitic acid from the Tournefortia hirsutissima L. plant was carried out by microwave-assisted extraction. The dried leaves of the plant were introduced in a solution of $150 \mathrm{ml}$ of ethanol and placed in the flask. The contents of the flask were stirred until the solution was homogenized and the mixture was heated in the microwave for 4 minutes, stopping each time it began to boil. Filtration was done with a microfilter of 0.45 .

\section{Cream elaboration}

The cetyl alcohol and essential oils were heated until they melted, then the Shea Butter was added until it was also melted. Water was added at $60^{\circ} \mathrm{C}$ and stirred until the emulsion was formed and the consistency did not change anymore. The Argan oil and Squalane were introduced, stirred again. Subsequently, the Panthenol was added. Finally, the $\mathrm{pH}$ was measured, obtaining a $\mathrm{pH}$ of 6 .

\section{Cream test on Staphylococcus aureus}

The test organism used was Staphylococcus aureus ( $S$. aureus, ATCC 35696). $100 \mu \mathrm{l}$ of liquid culture medium with $S$. aureus was placed in agar culture media and scattered with a sterile Drigalsky spatula. Sterile filter paper discs $(0.7 \mathrm{~cm})$ with the plant extract and the cream were placed on the culture plates and were incubated at $35^{\circ} \mathrm{C}$. As negative control, it was used culture places without solvents in filter paper discs. After $24 \mathrm{~h}$ of incubation, the diameter in $\mathrm{cm}$ of the inhibitory zones was recorded.

\section{Results}

\section{Investigation of compounds}

The components found in a greater proportion in the plant are: 3,7,11,15-tetramethyl-2-hexadecen-1-ol (14.92\%),

$1,2-$ benzenedicarboxylic acid, mono (2-ethylhexyl) ester (21\%), 2,2'methylene bis $(4.53 \%$, 9-octadecenoic acid ethyl ester (4.11\%), Ethyl ester hexadecanoic acid (4.77\%) and $\gamma$-sitosterol (16.42\%). We describe each component as well as its applications. 3,7,11,15-tetramethyl-2-hexadecen-1-ol (14.92\%): It is a diterpene alcohol obtained from the degradation of chlorophyll and has been used in the synthesis of Vitamins E and K. Additionally, it has sedative and anxiolytic effects through interaction with the GABAA receptor. And it has been explored as an antischistosomal agent [4].

1,2-benzenedicarboxylic acid, mono (2-ethylhexyl) ester (21\%): Also known as (2-ethylhexyl) hydrogen phthalate [5]. Responsible for inducing apoptosis in Sertoli cells by disruption of binding complexes [6]. It is noteworthy that having a boiling temperature of $25^{\circ} \mathrm{C}-27^{\circ} \mathrm{C}$ this is eliminated during the extraction process since temperatures above $80^{\circ} \mathrm{C}$ are handled.

2,2-methylene bis (4.53\%): Also known as "Antioxidant 2246". Prevents the aging of natural rubber, synthetic rubber and synthetic resin by ultraviolet rays and metallic compounds. In addition, it avoids the change of the physical property and the color of the resins [7].

9-octadecenoic acid ethyl ester (4.11\%): Also known as Elaidic acid [8]. It is the most abundant and distributed unsaturated fatty acid in nature. It is used commercially in the preparation of oleates and lotions, and as a pharmaceutical solvent.

Ethyl ester hexadecanoic acid (4.77\%): Also known as palmitic acid, induces Erk 1/2 and Akt responses. These molecules are involved in the activation of $\mathrm{p}$-Erk1/2 and p-Akt, which modulate basic biological processes such as proliferation and keratinocyte migration [9], cellular type predominant in the epidermis and responsible for the processes of inflammation and dermal repair. However, the excessive migration and proliferation of keratinocytes induces oxidative stress through the excessive generation of Reactive Oxygen Species (ROS). Wound healing rates decrease as cell damage increases due to ROS production, which accumulates over time. Results show that old and young keratinocytes respond to oxygen tension differently and support the hypothesis that keratinocyte migration is affected by the ability to eliminate ROS. $\gamma$-sitosterol (16.42\%).

It has anti-diabetic, anti-angiogenic, antiviral, anti-carcinogenic, antimicrobial and anti-inflammatory functions, besides being a strong antioxidant, which prevents the excessive production of Reactive Oxygen Species (ROS), keratinocytes [9].

\section{Extraction methods}

In the extraction methods of Tournefortia hirsutissima L. the following results were obtained.

Steam distillation method: It was obtained $10 \mathrm{ml}$ of distilled and it was added $2 \mathrm{ml}$ of ethyl acetate to facilitate the separation. Despite this, it was obtained only droplets for the extract. The total collection of oils was $1 \mathrm{ml}$ with a yield of $0.02043 \mathrm{ml} / \mathrm{g}$ of Tournefortia hirsutissima L.

Microwave assisted extraction (MAE): It was obtained $2 \mathrm{ml}$ of extract with an efficiency of $0.0408 \mathrm{ml} / \mathrm{g}$.

In the extraction methods of Carrot the following results were obtained.

Solvent extraction of beta-carotene and retinol: It was obtained $2 \mathrm{ml}$ of final product with a final yield of $0.02 \mathrm{ml} / \mathrm{g}$.

Microwave assisted extraction (MAE): It was obtained $10 \mathrm{ml}$ with a yield of $0.04 \mathrm{ml} / \mathrm{g}$. 
Page 3 of 4

\section{Cream elaboration}

An analysis was carried out to know the sterility of our product following the Manual of Microbiological Analysis of the FDA. Using Sodium Laureth Sulfate medium.

Three replicates of the inoculation with the cream sample were performed and none had gas inside, which is indicative that the sample does not possess coliforms such as Escherichia coli and Klebsiella pneumoniae. In addition, nutrient agar media were inoculated with the three cream samples for the isolation and isolation of microorganisms that did not require a demanding nutritional requirement. The first media had not growth of UFC. The second media had two UFC, and the third media had one UFC.

Three samples of the cream were diluted with Milli-Q water to determine their acidity level with $\mathrm{pH}$ strips. The same $\mathrm{pH}$ of 6 were obtained in the three samples.

\section{Discussion}

Therefore, from this investigation, it is determined that the compounds that help to healing are the $\gamma$-sitosterol, present in a $16.42 \%$ in the plant, and Ethyl ester hexadecanoic acid, present in a $4.77 \%$. With this research, it is determined that exist components in the plant which accelerate the regeneration of cells and ensures that cream manufactured has healing effects. The extraction protocol can be seen in Table 1 for the extraction of palmitic acid and gamma sitosterol and Table 2 for the extraction of beta-carotene and retinol. The Microwave Assisted Extraction obtained the best yields with a final product of 10 $\mathrm{ml}$ of beta-carotene extract with a yield of $0.04 \mathrm{ml} / \mathrm{g}$. Compared with the solvent extraction $(0.02 \mathrm{ml} / \mathrm{g})$, the MAE was twice as efficient. In the case of Tournefortia hirsutissima L., $2 \mathrm{ml}$ of the compounds of interest were obtained, so that their efficiency was $0.0408 \mathrm{ml} / \mathrm{g}$ compared to distillation, which had a yield of $0.02043 \mathrm{ml} / \mathrm{g}$.

\begin{tabular}{|l|l|}
\hline \multicolumn{2}{|l|}{ Palmitic Acid and Y-sisterol } \\
\hline Method & Yield \\
\hline Distillation & $0.02043 \mathrm{ml} / \mathrm{g}$ \\
\hline MAE & $0.0408 \mathrm{ml} / \mathrm{g}$ \\
\hline
\end{tabular}

Table 1: Comparison of the two extraction methods of palmitic acid and Y-sisterol by MAE and distillation.

\begin{tabular}{|l|l|}
\hline \multicolumn{2}{|l|}{ Retinol and betacarotenes } \\
\hline Method & Yield \\
\hline Distillation & $0.020 \mathrm{ml} / \mathrm{g}$ \\
\hline MAE & $0.04 \mathrm{ml} / \mathrm{g}$ \\
\hline
\end{tabular}

Table 2: Comparison of the two extraction methods of beta-carotene and retinol by MAE and distillation.

\section{Cream test on Staphylococcus aureus}

The inhibitory zones reached $1.9 \mathrm{~cm}$ in samples used the cream and $0.9 \mathrm{~cm}$ with the plant extract. In every case, the negative controls showed no antibacterial activity. The results are shown in Tables 3 and 4.

\begin{tabular}{|l|l|l|}
\hline Plate & Diameter $\mathbf{1}(\mathbf{c m})$ & Diameter $\mathbf{2}(\mathbf{c m})$ \\
\hline 1 & 1.9 & 1.9 \\
\hline 2 & 1.4 & 1.5 \\
\hline 3 & 1.5 & 1.7 \\
\hline
\end{tabular}

Table 3: Diameter represents the inhibition zone of the cream on Staphylococcus aureus.

\begin{tabular}{|l|l|l|}
\hline Plate & Diameter $\mathbf{1}(\mathbf{c m})$ & Diameter $\mathbf{2}(\mathbf{c m})$ \\
\hline 1 & 0.8 & 0.9 \\
\hline 2 & 0.9 & 0.8 \\
\hline 3 & 0.9 & 0.1 \\
\hline
\end{tabular}

Table 4: Diameter represents the inhibition zone of the plant extract on Staphylococcus aureus.

\section{Conclusion}

In this investigation, it was concluding that $\gamma$-sitosterol and Ethyl ester hexadecanoic acid (palmitic acid) are the compounds of Tournefortia hirsutissima L. that produce the healing. Furthermore, the plant has an antibacterial activity which could prevent wound infections. Also, the most efficient method to extract the components is MAE.

\section{Acknowledgement}

The authors are thankful to the Instituto Tecnológico y de Estudios Superiores de Monterrey, Alma Cuellar Sánchez and Arianna Beatriz Gallegos Pineda for providing the necessary facilities for the preparation of the paper.

\section{References}

1. Yoon S, Lee K, Kim D, Hwang D, Won K, et al. (2017) Effect of absolute from Hibiscus syriacus L. flower on wound healing in keratinocytes. Pharmacognosy Magazine 13: 85-89.

2. General Hospital of Mexico (2015) General session transcendence of the integral and specialized attention of the person affected by acute and / or chronic injuries and their family. February 14, 2017 of General Hospital of Mexico site.

3. Hernández M, Rojas F, Portillo R, Salgado M, Petranovskii V, et al. (2016) Textural Properties of Hybrid Biomedical Materials Made from Extracts of Tournefortia hirsutissima L. Imbibed and Deposited on Mesoporous and Microporous Materials. Journal of Nanomaterials 2016, 10. 7 out of February 2017, De ournal of Nanomaterials Database.

4. Cyman Chemical (2007) Phytol. April 21, 2017 de cayman chemical.

5. National Onstitute of Standards and Technology (2011) Ethyl elaidate. Abril 21, 2017, de Nationala Institute of standards and technology.

6. Chembook. (2017) Phthalic acid mono-2-ethykhexyl ester. April 21, 2017 from Chembook.

7. Gauyou Auxilary Factory (2007) Antioxidant 2246. April 22, 2017 from Gauyou auxiliary.

8. Fitzpatrick $\mathrm{T}$ (2003) Inflammatory disorders based on reactivity and deregulation of lymphocytes. In Dermatology in General Medicine. Spain: Panamericana.

9. Ross C, Alston M, Bickenbach J, Aykin-Burns N (2011) Oxygen tension changes the rate of migration of human skin keratinocytes in an agerelated manner. US National Library of Medicine National Institutes of Health 20: 58-63. 